\title{
The Care Situation, Stigmatization and Requirements of People with Mental Health Problems in Rural Areas
}

\author{
Brigitte Jenull ${ }^{1}$, Ingrid Salem ${ }^{1}$, Eva Mir $^{2}$ \\ ${ }^{1}$ Department of Psychology, Alpen-Adria-Universität, Klagenfurt, Austria \\ ${ }^{2}$ Carinthia University of Applied Sciences, Feldkirchen, Austria \\ Email: brigitte.jenull@aau.at
}

Received September $11^{\text {th }}, 2012$; revised October $15^{\text {th }}, 2012$; accepted October $27^{\text {th }}, 2012$

\begin{abstract}
With a lifetime prevalence of about $27 \%$ mental disorders are amongst the most common diseases. They typically are of chronic course, thus affecting not only the respective people, but also the social surroundings. In order to provide mental health care in best possible proximity to their homes, transparency of the services offered and a rapid access are needed. The present study aims at defining the problems and requirements of rural mental health in a Carinthian region (Austria). The users $(n=46)$ and the family members $(n=37)$ were surveyed regarding their individual situation, the current strains and the level of social support. Additionally, expert interviews $(n=44)$ were conducted and analysed by using qualitative content analysis. Findings revealed that much of mental health care is delivered by primary care physicians and is too often limited to medication. As far as mobile psychosocial offers and expert staff are concerned, all of our interviewed people locate serious flaws and need for action. The present study concludes that there is urgent need to improve the care situation in rural areas. Case and care management and initiatives to reduce stigmatization are of paramount importance.
\end{abstract}

Keywords: Mental Illness; Community-Based Mental Health Services; Unmet Medical Need; Stigmatization

\section{Introduction}

Epidemiological studies show that mental disorders are amongst the most common diseases within the population (Knapp, McDaid, Mossialos, \& Thornicroft, 2007; Wittchen \& Jacobi, 2005). Although every fourth person in the European Union is concerned by mental health problems, $80 \%$ do not receive appropriate treatment even yet the standard of knowledge in prevention and therapy is high (Demyttenaere et al., 2008; Siddiqi \& Siddiqi, 2007; WHO, 2006). Medical needs in rural areas are unmet due to shortage of qualified staff. Furthermore there are often barriers by the geographical location, socio-cultural events and economic conditions to access services (Zanjani \& Rowles, 2012). Low income and insufficient education hamper early intervention and treatment of mental health problems (Kumar, 2011; McElmurry, Marks, Cianelli, \& Mamede, 2002; Merkel, 2004). Gaps in patient-centered care are caused by inadequate strategies and financing as most resources are still directed towards hospital treatment (WHO, 2006).

Most people with mental health problems consult primary care physicians but studies demonstrate that a substantial part of the mental diseases presented, are not accurately diagnosed (Gamm, Tai-Seale, \& Stone, 2002; Siddiqi, \& Siddiq, 2007; Walters \& Tylee, 2006). This is explained by insufficient training of primary care physicians and other variables like trivialization of mental health problems by the patients. Many people with mental diseases have doubts about effective treatment possibilities or hope, they can handle the problem without seeing a health professional (Verhaak, Schellevis, Nuijen, \& Volkers, 2006). In addition mental diseases are often not diagnosed at the initial contact with the physician and further consulta- tions are mostly too brief for in-depth conversation since the average time spent with the physician does not exceed 13 to 16 minutes (Bazelon Center for Mental Health Law, 2006).

Apart from unavailable or inadequate care, stigmatisation is the most severe problem of patients with mental health problems (Corrigan, Kerr, \& Knudsen, 2005; Health Scotland, 2008; Kelly, 2006; Mueller et al., 2006). This assumed stigma prevents patient contact with psychosocial services, thus causing delay or inhibition of early diagnosis and intervention (Rüsch et al., 2009; Schomerus \& Angermeyer, 2008). Persons living in rural areas feel even more stigmatized (Gamm et al., 2002). There is a difference between societal stigma and personal attitude towards being affected by mental illness. Persons concerned boost stigmatization by internalizing discrimination and prejudice in the society. This leads to a loss in self-belief and self-confidence resulting in an unfavorable prognosis (Corrigan et al., 2005). In order to avoid exclusion from society of persons living in rural areas and suffering from mental diseases, the phenomenon of stigmatization needs consideration.

The study presented informs about patient-centered care offers for mentally ill people living in a rural area in Carinthia (Austria). Austria with a total area of $83,879 \mathrm{~km}^{2}$ and $8,420,900$ inhabitants consists of 9 provinces; Carinthia as one of those has 558.056 inhabitants. 18,766 persons live in the study area, this Carinthian district has with 23 persons per $\mathrm{km}^{2}$ one of the lowest population density in Austria. It is a rural region, and more traditionally oriented. The inhabitants live mainly from tourism. The net annual income of Carinthia salaried employed persons in 2010 was about 23,500 Euro for men and 15,200 Euro for women. It is slightly below the average Austrian (Statistik Austria, 2012). Undisputed is the strain such patients 
endure - thus the aim of the study is to show requirement of patient-centered care offers as seen by health care providers, patients and relatives. In a second step the experienced burden of disease as well as perceived assistance was examined. These results lead to recommendations for coordinated area-wide and demand-oriented care.

\section{Methodology}

\section{Study Design}

The present study is a cross-sectional evaluation and was designed as census. Data were collected over an 8-month-period. A mixed-method approach was chosen to answer the research question. This approach integrates subjective views of experts, of users as well as members to obtain comprehensive and relevant results about the district (Creswell \& Plano Clark, 2007). Qualitative and quantitative methods were used within the meaning of triangulation-designs.

\section{Measures}

Three target groups were examined to ensure a multi-perspective data base. For each target group an own methodologycal approach was chosen. Three project employees were responsible for the procedure of the study. These project employees got explanations and were given a coaching during the whole study.

\section{Interviews with Experts}

Experts were asked about the psychosocial overall situation of the district. The interviews lasted about 20 minutes and were conducted in the respective facilities. Physicians, psychotherapists, social workers, psychologists as well as caregiver in psychosocial institutions of the district were interviewed. In this context, guided interview is a suitable form of elevation. The interview, based on the theoretical background presented earlier, (e.g., Gamm et al., 2002; Merkel, 2004) outlined three central questions:

1) Percentage of mentally ill people in the district;

2) Basis information of diagnosis;

3) Main focuses and problems of supply.

\section{Questionnaire-Based Survey with Users}

Users were interviewed with a predominant quantitative questionnaire: socio-demographic data, one item to capture stigmatization, a care-burden-scale (Salewski \& Ostendorf, 2003) as well as a shortform of the questionnaire about social assistance (F-SozU K-22) (Fydrich, Sommer, \& Brähler, 2007) were used.

The adapted care-burden-scale includes 26 items and is divided into five subscales: social burden, sanitary stress, temporal stress, financial stress, demands of the family member and relationship with family member. The responses to items were rated on a 5-point-scale (never, rarely, sometimes, often and always). Scales follow a theoretical methodology and dispose of interne consistencies between $\alpha=.71$ and $\alpha=.91$ (Salewski $\&$ Ostendorf, 2003). The questionnaire about social assistance (F-SOZU K22) includes 22 items and it is possible to calculate a total value. The sub-scales "emotional support", "practical support", "social integration", "availability of a person of trust" and "satisfaction with social support" are documented fac- tor-analytically and have a good reliability $(\alpha=.91)$ and positive results of validity (Fydrich et al., 2007). The questions are answered on a 5-point scale rated from "not true" to "true".

\section{Questionnaire-Based Survey with Family Members}

The questionnaire for family members bases on the same questions as the questionnaire for users, because so comparisons are possible. Thus the instrument for users and for family members was the same.

The experts gave both survey methods to the clients as well as to their family members.

Data analysis and representation of results, with which it is possible to find something out about institutions or persons, were not used. This was important to guarantee study participants anonymity. The completed questionnaires were collected in the facility and then given to the project management.

\section{Data Collection and Analysis}

The transcripts of all expert-interviews were used for following qualitative content analysis. Structured, deductive and inductive techniques were used (Mayring, 2007).

The questionnaires for users and their family members were analysed with classical statistical analysis methods (arithmetic mean comparisons by t-test and univariate variance analysis). SPSS 20.0 (Bühl, 2011) was used for these statistical analysis methods.

\section{Sample}

\section{Experts}

Experts were recruited about all local mental health facilities in the investigated area. A total of 44 experts took part in the study. 12 of the interviewees were physicians and the other 32 people are in leading positions in psychosocial facilities and belong to different occupational groups (social work, psychology, psychotherapy $\cdots$ ). The participation rate of experts was $84 \%$.

\section{Users and Family Members}

In the course of interviews a possible distribution of questionnaires to family members and persons concerned was discussed with experts. For reasons of anonymity no sampling was conducted and the questionnaires were distributed by the experts. 83 of 300 questionnaires were returned. This correspond a participation rate of $31 \%$ of users and $25 \%$ of family members. 26 female clients and 19 male clients $(n=46, n=1$ without description) of psychosocial facilities in the explored district were on average $58( \pm 20)$ years (range: 6 - 93 years) old. 16 persons were married, 12 people were single and 18 lived separate respectively were divorced or widowed at time of the study. 18 clients lived alone and 16 in a partnership or with parents together and 12 lived together with other family members. For 25 persons family members took care (14 from partners, 11 from other family members) and 19 persons were looked after institutional, for example by mobile services. Two persons did not provide information.

37 family members ( 25 women, 12 men) took part in the study. The family members were on average $53( \pm 13)$ years (range: 27 - 82 years) old. At time of the study 17 persons were employed. Bulk of family members were married $(n=30)$, 
three were single and one person lived separately and three persons did not provide information. The male family members are significantly older than the female $(\mathrm{t}=-2.738, \mathrm{df}=31, p$ $=.010)$.

\section{Results}

\section{Assessment of Patient-Centered Care (Expert Interviews)}

Experts from a wide range of professions were questioned in order to get an extensive view of the available logistics. Due to the varied approaches by the different professions, results were analyzed separately (medical doctors $(\mathrm{n}=12)$ and psychosocial health professionals $(n=32)$ ).

Primary care physicians reported that $20 \%$ to $50 \%$ of their patients had mental health problems. Three doctors made most diagnoses during the conversations held with their patients, also because they had known them for a long time. Two thirds of the physicians referred their patients to specialists or to psychiatric departments in the nearest hospital whenever they suspected mental health problems. Ten of the twelve doctors emphasized antipsychotic medication and seven led an educational and counseling conversation, advising the patients on helpful and supportive steps to take.

The main focus in patient-centered care for mental diseases can be pin-pointed to a very basic provisioning.

We now present the results by defining the main categories within each domain giving some typical examples.

As can be seen in Table 1 perceived problems or shortcomings in Medicare are of ultimate concern. Living far from medical and psychosocial services is also mentioned. Most relevant seems the problem of stigmatization, which might jeopardize the utilization of offered services. Professionals also allude to the patients' fear regarding anonymity.

From their respective perspectives, clients, relatives and experts likewise ask for an improvement in patient-centered care (see Table 2). Experts in this field add the request for specialized staff, networking and publicly visible awareness training.

Table 1.

General problems of the existing supply system $(\mathrm{N}=44)$.

\begin{tabular}{|c|c|c|c|c|}
\hline Category & Definition & Statements & $\mathrm{n} 1=12$ & $\mathrm{n} 2=32$ \\
\hline Society & Stigmatization tabooization & $\begin{array}{l}\text { "There are big social fears of coming-out." } \\
\text { "There is especially in rural areas a lack of acceptance and } \\
\text { tolerance." } \\
\text { "... is ashamed ..." }\end{array}$ & 4 & 15 \\
\hline Inadequate supply & $\begin{array}{l}\text { Limited to medications lack of } \\
\text { alternatives }\end{array}$ & $\begin{array}{l}\text { "Medications are the standard." } \\
\text { "In our district there is a lack of institutions, } \cdots \text { a deficit in } \\
\text { psychiatric supply, psychotherapy ..." }\end{array}$ & 16 & 21 \\
\hline $\begin{array}{l}\text { Geographical } \\
\text { location }\end{array}$ & Long avenues difficult to use & $\begin{array}{l}\text { "It is difficult because our rural situation ... who drives every } \\
\text { week to a group therapy to city A or city B?" } \\
\text { "... it can take a long time that somebody comes truly ..." } \\
\text { "Medical care is on the back burner." }\end{array}$ & 3 & 11 \\
\hline Savings & Financial aspects & $\begin{array}{l}\text { "Everywhere is saved, } \cdots \text { additional offers would be gut, but } \\
\text { not financed." }\end{array}$ & 10 & 11 \\
\hline
\end{tabular}

Note: $\mathrm{n} 1=$ physicians; $\mathrm{n} 2=$ experts of psychosocial institutions

Table 2.

Desires for a better supply $(\mathrm{N}=155)$.

\begin{tabular}{|c|c|c|c|c|c|c|}
\hline Category & Definition & Statements & $\mathrm{n} 1$ & $\mathrm{n} 2$ & n3 & $\mathrm{n} 4$ \\
\hline $\begin{array}{l}\text { Improving the supply } \\
\text { system }\end{array}$ & $\begin{array}{l}\text { - Location-based offers (learning } \\
\text { assistance, day-care centers, work } \\
\text { projects, youth centre, } \cdots \text { ) } \\
\text { - Housing units near community for } \\
\text { chronically ill people (psychiatric } \\
\text { care) } \\
\text { - A centre for emergency and crises } \\
\text { - } \quad \text { psychosocial care } \\
\text { self-help groups }\end{array}$ & $\begin{array}{l}\text { "A centre for emergency and crises, } \cdots \text { Hermagor } \\
\text { as a central place, to get quickly in different valleys." } \\
\text { "... a psychotherapeutic ambulance...free of } \\
\text { charge" } \\
\text { "... mobile psychosocial care would be } \\
\text { desirable..." }\end{array}$ & 6 & 22 & 31 & 21 \\
\hline Public relations & $\begin{array}{l}\text { - } \quad \text { Awareness training } \\
\text { - } \quad \text { Awareness raising }\end{array}$ & $\begin{array}{l}\text { “... more awareness training...information, what } \\
\text { possibilities are there ..." } \\
\text { "more awareness training for family members who } \\
\text { care for somebody, } \cdots \text { adolescents, ..in schools ..." } \\
\text { "talk about topics without taboo ..." }\end{array}$ & & 18 & & 1 \\
\hline Networking & $\begin{array}{ll}- & \text { Interdisciplinary work } \\
\text { - } & \text { Cooperation } \\
\text { - } & \text { Interface management }\end{array}$ & $\begin{array}{l}\text { "Health care system needs increased collaboration } \\
\text { with physicians ..." } \\
\text { "... an intermediary between family doctor, hospital } \\
\text { and patient/family members, .. trained people, who } \\
\text { network and coordinate." }\end{array}$ & & 22 & & \\
\hline Experts & - $\quad$ Staff increasing & $\begin{array}{l}\text { "... workers with flexible applicability ..." } \\
\text { “... take stock of clientele more intensively ..." }\end{array}$ & 6 & 15 & 1 & \\
\hline
\end{tabular}

Note: $\mathrm{n} 1$ = physicians; $\mathrm{n} 2$ = experts of psychosocial institutions; $\mathrm{n} 3=$ clients; $\mathrm{n} 4$ = family members. 


\section{Experience of Strain and Support}

The investigation yielded interesting results: consumers of patient-centered care or mobile care services showed significantly lower signs of health stress than patients looked after by relatives $(\mathrm{F}(2,40)=4.463, p=.018)$. These patients were also burdened by their relationship towards the family member taking care of them $(\mathrm{F}(2,40)=3.464, p=.041)$ more than patients who were cared for institutionally.

The form of housing-living alone, with a partner or other family members - is associated with experience of burden and support of the clients: The univariate analysis of variance showed that affected people, who live alone have significantly lower values on the scale of health burden compared to affected people, who live together with a partner or family members $(\mathrm{F}(2,42)=5.334, p=.009)$. Also in the subscale "make demands" was a significant difference: affected people, who live alone, judge their demands significantly lower than affected people, who live with family members $(\mathrm{F}(2,41)=3.699, p$ $=.034$ ). Persons concerned, who live together with other family members have significantly less frequently a person of trust in their social network $(\mathrm{F}(2,39)=3.939, p=.028)$ and they are less socially integrated $(\mathrm{F}(2,39)=2.917, p=.046)$. Otherwise there were no statistically noticeable differences between the groups.

Gender differences were shown in the experience of burden and support of the family members. Male family members judge the temporal burden of care significantly higher than women ( $\mathrm{t}$-test for independent samples, $\mathrm{t}=-2.413, p=.022$ ). Female family members judge emotional support higher $(\mathrm{t}=$ $1.956, p=.049$ ). Three groups of age were formed to explore a possible association of age and the experience of burden and support: people under 45 years, 45 to 60 , and people over 60 . Health of family members over 60 was significantly higher burdened $(\mathrm{F}(2,29)=4.432, p=.021)$ and they reported more financial problems than younger family members $(\mathrm{F}(2,29)=$ $3.352, p=.049$ ). Older family members reached significantly lower total values in F-SozU K-22 than family members under 45 years $(\mathrm{F}(2,29)=3.373, p=.048)$. Over 60 years old get significantly less support than younger family members.

\section{Experience of Stigmatization}

As can be seen in Figure 1, half of the persons concerned often or even permanently feel excluded from society by their impairment. Two thirds of the relatives did not (or seldom) feel excluded due to the illness of their family member. For the majority of patients $(73 \%)$ stigmatization is part of their daily life.

\section{Discussion}

The study presented provides insight into the outpatient care reality of patients with mental health problems in a small Carinthian district, thus meeting the demand of observational research by including users and their relatives of patients-centered care (Riedel-Heller, Bramesfeld, Roick, Becker, \& König, 2008). With respect to the variability and heterogeneity of rural areas (Philo, Parr, \& Burns, 2003) the results presented here should be considered only valid for the studied area.

Literature maintains that primary care physicians are the first point of contact regarding mental health problems (Gamm et al., 2002; Walters \& Tylee, 2006). Medical experts in the investigated area had a substantive proportion of patients with mental health diseases, reports ranging between 20 and 50 percent. Manthorpe, Moriarty, Stevens, Hussein and Sharif (2012) noted in their study that it is important to improve the situation of the patient and their family members as well as to provide the practitioners a forum to discuss relevant problems. For us it seems to be a main point that practitioners get support in terms of training and supervision in order to meet the varying needs of their patients.

The major problem of these patients is the high level of stigmatization noticeable within their surroundings (Health Scotland, 2008). While struggling with symptoms of their mental health problems, they have little chances of finding employment and thus structuring their daily life (Rüsch, Angermeyer, \& Corrigan, 2005). This topic of taboo and exclusion, relevant to society, leads to a social retreat of patients with mental illness. They prefer to hide their problems, which hampers treatment in an early stage of the disease. In order to keep their problems under cover, people living in rural areas prefer to seek advice or help from inconspicuous persons instead of consulting specialists.

A possible proposal for helpful solutions might be the construction of larger social networks (Burns, 2007; Lewis, Baeza, \& Alexander, 2008) where people struck by (mental) diseases are taken care of by an interdisciplinary team. After a first diagnose, this center should provide a plan for crises and consecutive

\section{Stigmatization family members and clients}

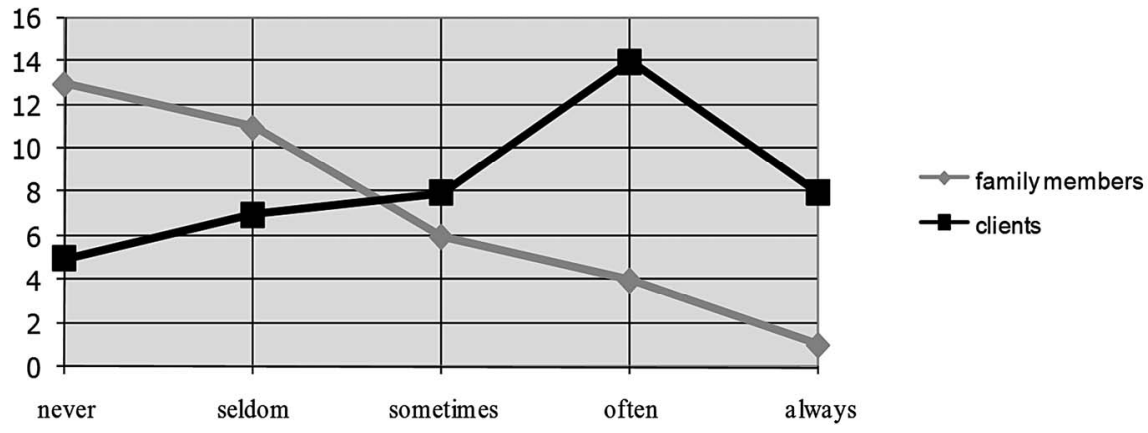

Figure 1.

Stigmatization family members and clients. 
therapy and coordinate the whole process including contact with relatives and family.

All interview partners emphasized the necessity of amelioration in patient-centered care, including psychoeducational activities and work-related training. Counteraction is needed for discrimatory comments and wrong accusations such as e.g. spreading rumours about higher crime rates in persons with mental diseases. Affected patients have to be supported by empowerment and dialogue or discourse with all parties concerned. The dialogue of professional experts with concerned patients gains an additional dimension by including relatives and keeping the societal context in mind (Bombosch, Hansen, \& Blume, 2004). This perspective creates equality between patient, relatives and carers.

Relatives report an increase of strain by their own aging. While their health problems increase, social support, integration in civic life and life-satisfaction decrease.

Older community members of this rural area, who are burdened by the care for a mentally ill relative, are a high priority target group for intervention.

Regarding current care concepts, the control sample of patients cared for in an institutional setting, showed a lower level of strain than persons cared for by their relatives. The support of each individual in the areas of housing, work and recreational activities is a consequential necessity. In case of care being provided by relatives or close family, they need to be supported by offering them psychoeducation, encouragement and work relief.

Since the seventies psychiatric patient-centerd care in Austria has undergone quite a couple of renewing initiatives such as reduction of inpatient bedding, an increase of community based services and socio-professional reintegration of mentally ill persons into daily community life (BMGFJ, 2005; Zechmeister, 2004).

A couple of urban regions in Austria (Schöny \& Katschnig, 1991) have a well-developed extramural care system whereas rural areas lack of expert staff as well as specific day-structuring facilities.

More than a decade later Merkel (2004) as well as Blackstock, Innes, Cox, Smith and Mason (2006) arrive at similar results and claim that in general, more attention should be paid to the rural mental health, because the shortage in rural communities is dramatic due to cultural economic and geographical reasons. Our study confirms these findings: Treatment of patients with mental health problems in the examined community is reduced to minimal interventions without including further parties involved. There is a lack of qualified staff necessary to provide affordable and comprehensive treatment and care.

In general, more attention should be paid to the rural mental health.

\section{REFERENCES}

Bazelon Center for Mental Health Law (2006). Get it together. How to integrate physical and mental health care for people with serious mental disorders. URL (last checked 14 August 2012).

http://www.bazelon.org./issues/mentalhealth/publications/getittogeth er/execsumm.htm

Blackstock, K. L., Innes, A., Cox, S., Smith, A., \& Mason, A. (2006). Living with dementia in rural and remote Scotland: Diverse experiences of people with dementia and their carers. Journal of Rural Studies, 22, 161-176. doi:10.1016/j.jrurstud.2005.08.007

BMGFJ, Bundesministerium für Gesundheit, Familie und Jugend
(2005). Das Gesundheitswesen in Österreich. Horn: Berger.

Bombosch, J., Hansen, H., \& Blume, J. (2004). Trialog praktisch. Neumünster: Paranus.

Bühl, A. (2011). SPSS 20. Einführung in die moderne datenanalyse (13th ed.) (Introduction to modern data analysis). München: Pearson.

Burns, T. (2007). Community mental health teams. Psychiatry, 6, 325328. doi:10.1016/j.mppsy.2007.05.009

Corrigan, P., Kerr, A., \& Knudsen, L. (2005). The stigma of mental illness: explanatory models and methods for change. Applied and Preventive Psychology, 11, 179-190. doi:10.1016/j.appsy.2005.07.001

Creswell, J., \& Plano Clark, V. (2007). Designing and conducting mixed methods research. Thousand Oaks: Sage.

Demyttenaere, K., Bonnewyn, A., Bruffaerts, R., De Girolamo, G., Gasquet, I., Kovess, V., Haro, J., \& Alonso, J. (2008). Clinical factors influencing the prescription of antidepressants and benzodiazepines. Results from the European study of the epidemiology of mental disorders (ESEMeD). Journal of Affective Disorders, 110, 84-93. doi:10.1016/j.jad.2008.01.011

Fydrich, T., Sommer, G., \& Brähler, E. (2007). Fragebogen zur Sozialen Unterstützung (F-SozU) (survey of social support). Manual. Göttingen: Hogrefe.

Gamm, L., Tai-Seale, M., \& Stone, S. (2002). White paper: Meeting the mental health needs of people living in rural areas. Galveston, TX: Department of Health Policy and Management School of Rural Public Health, Texas A\&M University System Health Science Center College Station,

Health Scotland (2008). Stigma: A guidebook for action. Tackling the discrimination, stigma and social exclusion experienced by people with mental health problems and those close to them. Edinburgh: Health Scotland.

Kelly, B. (2006). The power gap: Freedom, power and mental illness. Social Science \& Medicine, 63, 2118-2128. doi:10.1016/j.socscimed.2006.05.015

Knapp, M., McDaid, D., Mossialos, E., \& Thornicroft, G. (2007). Mental health policy and practice across Europe. The future direction of mental health care. Maidenhead: Open University Press.

Kumar, A. (2011). Mental health services in rural India: Challenges and prospects. Health, 3, 757-761. doi:10.4236/health.2011.312126

Lewis, J., Baeza, J., \& Alexander, D. (2008). Partnerships in primary care in Australia: Network structure, dynamics and sustainability. Social Science \& Medicine, 67, 280-291. doi:10.1016/j.socscimed.2008.03.046

Manthorpe, J., Moriarty, J., Stevens, M., Hussein, S., \& Sharif, N. (2012). Promoting the mentalwell-being of older people from black and minorityethnic communities in United Kingdom rural areas: Findings from an interview study. Journal of Rural Studies, 28, 406411.

Mayring, P. (2007). Qualitative inhaltsanalyse (qualitative content analysis). Weinheim: Deutscher Studien Verlag.

McElmurry, B., Marks, B., Cianelli, R., \& Mamede, M. (2002). Primary health care in the Americas: Conceptual framework, experiences, challenges and perspectives. Washington DC: Pan American Health Organisation.

Merkel, L. (2004). Rural mental health. URL (last checked 24 January 2007).

http://www.healthsystem.virginia.edu/internet/psych-training/semina rs/rural-mental-health-1-22-03.pfd

Mueller, B., Nordt, C., Lauber, C., Rueesch, P., Meyer, P., \& Roessler, W. (2006). Social support modifies perceived stigmatization in the first years of mental illness: A longitudinal approach. Social Science \& Medicine, 62, 39-49. doi:10.1016/j.socscimed.2005.05.014

Philo, C., Parr, H., \& Burns, N. (2003). Rural madness: A geographical reading and critique of the rural mental health literature. Journal of Rural Studies, 19, 259-281. doi:10.1016/S0743-0167(03)00005-6

Riedel-Heller, S., Bramesfeld, A., Roick, C., Becker, T., \& König, H.-H. (2008). Der ruf nach mehr versorgungsforschung (the need for more health services research). Psychiatrische Praxis, 35, 157-159. doi:10.1055/s-2008-1067424 
Rüsch, N., Angermeyer, M., \& Corrigan, P. (2005). Mental illness stigma: Concepts, consequences, and initiatives to reduce stigma. European Psychiatry, 20, 529-539. doi:10.1016/j.eurpsy.2005.04.004

Rüsch, N., Corrigan, P. W.,Wassel, A., Michaels, P., Larson, J. E., Olschewski, M., Wilkniss, S. \& Batia, K. (2009). Self-stigma, group identification, perceived legitimacy of discrimination and mental health service use. British Journal of Psychiatry, 195, 551-552. doi:10.1192/bjp.bp.109.067157

Salewski, C., \& Ostendorf, M. (2003). Entwicklung eines Fragebogens zur Erfassung der Belastung einer alterstypischen Lebensaufgabe: Die Pflege-Belastungs-Skala (PBS) (development of a questionnaire for the assessment of the impact of age-related tasks: The nursing stress scale). In K. Eisfeld, U. Wiesmann, H.-J. Hannich, \& P. Hirtz (Eds.), Gesund und bewegt ins alter. Interdisziplinäre ansätze für eine community medicine (pp. 137-146). Butzbach-Griedel: AFRA.

Schöny, W., \& Katschnig, H. (1991). Die psychiatriereform in österreich am beispiel der angehörigenarbeit und der laienhilfe (The mental health reform in Austria). In M. Bauer, R. Engfer, \& J. Rappl (Eds.), Psychiatrie-reform in Europa (pp. 89-113). Bonn: Psychiatrie-Verlag.

Schomerus, G., \& Angermeyer, M. C. (2008). Stigma and its impact on help-seeking for mental disorders: What do we know? Epidemiologia e Psichiatria Sociale, 17, 31-37.

Siddiqi, K., \& Siddiqi, N. (2007). Treatment of common mental disorders in primary care in low- und middle-income countries. Transac- tions of the Royal Society of Tropical Medicine and Hygiene, 101, 957-958. doi:10.1016/j.trstmh.2007.04.006

Statistik Austria (2012). Österreich und seine bundesländer (Austria and its provinces). URL (lase checked 10 September 2012). http://www.statistik.at/web_de/services/wirtschaftsatlas_oesterreich/ oesterreich_und_seine_bundeslaender/index.html

Verhaak, P., Schellevis, F., Nuijen, J., \& Volkers, A. (2006). Patients with a psychiatric disorder in general practice: Determinants of general practitioners psychological diagnosis. General Hospital Psychiatry, 28, 125-132. doi:10.1016/i.genhosppsych.2005.11.001

Walters, P., \& Tylee, A. (2006). Mood disorders in primary care. Psychiatry, 5, 138-141. doi:10.1383/psyt.2006.5.4.138

WHO (2006). Psychische gesundheit: Herausforderungen annehmen, lösungen schaffen (Mental health: Facing the challenges, finding solutions). Kopenhagen: WHO-Regionalbüro für Europa.

Wittchen, H., \& Jacobi, F. (2005). Size and burden of mental disorders in Europe. European Neuropsychopharmacology, 15, 357-376. doi:10.1016/j.euroneuro.2005.04.012

Zanjani, F., \& Rowles, G. (2012). "We don't want to talk about that": Overcoming barriers to ruralaging research and interventions on sensitive topics. Jorunal of Rural Studies, 28, 398-405.

Zechmeister, I. (2004). Paradigm shift in mental health care: Challenges and approaches for financing a community mental health care system in Austria. Ph.D. Thesis, Wien: Wirtschaftsuniversität Wien. 